This item was submitted to Loughborough's Research Repository by the author.

Items in Figshare are protected by copyright, with all rights reserved, unless otherwise indicated.

\title{
Evaluating the impact and risk of pluvial flash flood on intra-urban road net- work: A case study in the city center of Shanghai, China
}

\section{PLEASE CITE THE PUBLISHED VERSION}

http://dx.doi.org/10.1016/j.jhydrol.2016.03.037

\section{PUBLISHER}

(C) Elsevier

VERSION

AM (Accepted Manuscript)

\section{PUBLISHER STATEMENT}

This work is made available according to the conditions of the Creative Commons Attribution-NonCommercialNoDerivatives 4.0 International (CC BY-NC-ND 4.0) licence. Full details of this licence are available at: https://creativecommons.org/licenses/by-nc-nd/4.0/

\section{LICENCE}

CC BY-NC-ND 4.0

\section{REPOSITORY RECORD}

Yin, Jie, Dapeng Yu, Zhane Yin, Min Liu, and Qin He. 2019. "Evaluating the Impact and Risk of Pluvial Flash Flood on Intra-urban Road Net- Work: A Case Study in the City Center of Shanghai, China". figshare. https://hdl.handle.net/2134/20960. 


\section{Accepted Manuscript}

Evaluating the impact and risk of pluvial flash flood on intra-urban road network: A case study in the city center of Shanghai, China

Jie Yin, Dapeng Yu, Zhane Yin, Min Liu, Qin He

PII:

$$
\text { S0022-1694(16)30142-1 }
$$

DOI: http://dx.doi.org/10.1016/j.jhydrol.2016.03.037

Reference:

HYDROL 21141

To appear in:

Journal of Hydrology

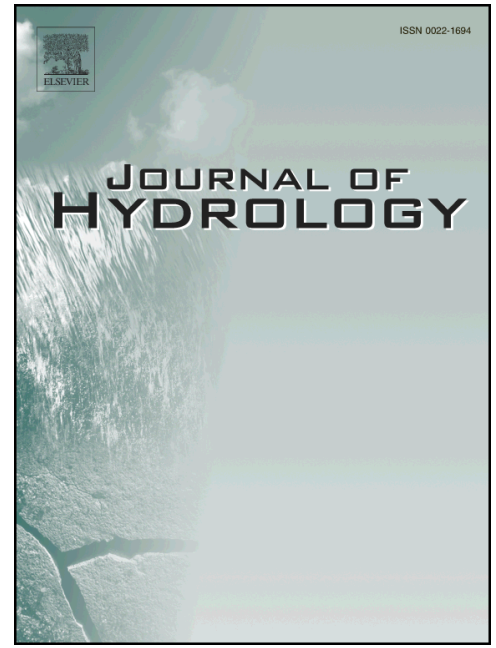

Received Date: $\quad 21$ January 2016

Revised Date: $\quad 17$ March 2016

Accepted Date: $\quad 19$ March 2016

Please cite this article as: Yin, J., Yu, D., Yin, Z., Liu, M., He, Q., Evaluating the impact and risk of pluvial flash flood on intra-urban road network: A case study in the city center of Shanghai, China, Journal of Hydrology (2016), doi: http://dx.doi.org/10.1016/j.jhydrol.2016.03.037

This is a PDF file of an unedited manuscript that has been accepted for publication. As a service to our customers we are providing this early version of the manuscript. The manuscript will undergo copyediting, typesetting, and review of the resulting proof before it is published in its final form. Please note that during the production process errors may be discovered which could affect the content, and all legal disclaimers that apply to the journal pertain. 
Evaluating the impact and risk of pluvial flash flood on intra-urban road network: a case study in the city center of Shanghai, China

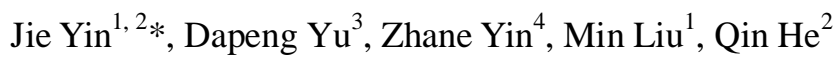

1 School of Geographic Sciences, East China Normal University, China

2 State Key Laboratory of Estuarine and Coastal Research, East China Normal University, China

3 Centre for Hydrological and Ecosystem Science, Department of Geography, Loughborough University, UK

4 Department of Geography, Shanghai Normal University, China

* Corresponding author e-mail address: rjay9@126.com

Address: 3663 North Zhongshan Road, Shanghai, China, 200062 
Abstract: Urban pluvial flood are attracting growing public concern due to rising intense precipitation and increasing consequences. Accurate risk assessment is critical to an efficient urban pluvial flood management, particularly in transportation sector. This paper describes an integrated methodology, which initially makes use of high resolution 2D inundation modeling and flood depth-dependent measure to evaluate the potential impact and risk of pluvial flash flood on road network in the city center of Shanghai, China. Intensity-Duration-Frequency relationships of Shanghai rainstorm and Chicago Design Storm are combined to generate ensemble rainfall scenarios. A hydrodynamic model (FloodMap-HydroInundation2D) is used to simulate overland flow and flood inundation for each scenario. Furthermore, road impact and risk assessment are respectively conducted by a new proposed algorithm and proxy. Results suggest that the flood response is a function of spatio-temporal distribution of precipitation and local characteristics (i.e. drainage and topography), and pluvial flash flood is found to lead to proportionate but nonlinear impact on intra-urban road inundation risk. The approach tested here would provide more detailed flood information for smart management of urban street network and may be applied to other big cities where road flood risk is evolving in the context of climate change and urbanization.

Keywords: Pluvial flash flood; Intra-urban; Road network; Risk assessment; Shanghai 


\section{Introduction}

Pluvial flash flood (PFF) is among the most common and destructive natural hazards, resulting in considerable direct losses (e.g. personal injury and property damage) and increasing indirect impacts (e.g. interruption of public services and economic activities), especially in the urbanized areas around the world (e.g. Ramos et al. 2005; Mejia and Moglen 2010; Smith et al. 2012; Wright et al. 2012). PFF is a rapid flood caused by heavy rain and can be distinguished from a regular pluvial flood by a short timescale, generally less than six hours. It is usually by their very fast evolution and occurs within minutes or a few hours of excessive rainfall (Naulin et al. 2013). There exists a broad consensus that the combined effect of climate change and rapid urbanization is generally recognized as the primary cause for more frequent, heavier rainfall-runoff (IPCC, 2013; Du et al. 2012; Suriya and Mudgal 2012; Zhou et al. 2012). Furthermore, the lack of anticipation of PFF events such as the unavailability of short-term forecasting and warning, combined with insufficient, postponed adaption measures (e.g. inadequate drainage capacity) largely limit the efficiency of urban flood risk management, leading to the enhanced consequences of these events in most cities.

In all the flood prone areas, urban road network may be the major assets affected first by inundations, which cause not only infrastructure damage but also transportation disruption, due to its low-lying nature compared to the neighborhood and high-density throughout urban territory. More seriously, almost half of the flash flood casualties involve people on flooded roads by trapping in their cars or by escaping in the rapid rise of open water (Drobot et al. 2007; Versini et al. 2010a). Over the past several decades, the significant disasters associated with street networks and PFF events have been frequently occurring in different urban environments such as New York and London in developed countries as well as Beijing and Bangkok in developing countries (Pitt 2008; Hung et al. 2009; NYC Emergency Management 2014). Road networks of China's cities are particularly vulnerable to PFF events as the conflict between rapid urbanization and the lagging urban 
(infrastructure) planning is emerging onto the surface. This is evidenced by the recent PFF events in major Chinese cities, including Beijing, Shanghai, Guangzhou, Shenzhen, Nanjing, and Hangzhou (Zhang et al. 2012). For example, the July 2012 PFF event in Beijing city led to widespread transportation disruptions and claimed 79 lives, among which a large number of fatalities were caused by road inundations (Yin et al. 2015).

Although there is a huge demand for understanding urban road network risk to PFFs, until now, very few work have attempted to systematically examine the potential impacts of flash flood events on urban road systems largely due to the lack of adequate data and observations concerning road flooding, difficulty in numerically modeling the PFF dynamics and the complexity of cascading effects resulting from temporary flooding on transportation systems (Suarez et al. 2005). Of the existing studies, a number of studies are often conducted for the purpose of flood emergency evacuation (e.g. Chang et al. 2007), accessibility loss (e.g. Sohn 2006) or traffic delay (e.g. Zhou et al. 2012), while some others address short-term (and even real-time) forecasting or warning of road inundation risk (RIR) at specific intersections of streams and roads. In terms of road flood risk assessment, the extension of distributed hydro-meteorological model to road network scan approach have been usually applied or tested in a number of regions. A representative methodology is Road Inundation Warning System (RIWS) which combines a rainfall-runoff model with a road inundation susceptibility analysis (Versini et al. 2010b). Chang et al. (2010) integrated a hydrologic model (PRMS), a 1D hydraulic model (HEC-RAS) and a travel forecast model into an assessment framework of urban flooding and transportation systems. Moreover, a LRSRM (Local Regional Scale Risk Model) was designed to identify the interruption of a road network due to a hazardous event from a multi-scale perspective by using the biclustering technique (Freiria et al. 2014). The previous studies, however, mainly focus on regional (basin) scale and intercity level, paying little attention to PFF-induced RIR at the intra-urban level. Also, they can not explicitly provide detailed information of 2D surface flood routing on urban road network in time and space to allow a real-time risk management. In recent years, the development of simplified raster-based flood models (e.g 
LISFLOOD and FloodMap) combined with the existing high resolution LiDAR (i.e. airborne and terrestrial laser scanners) techniques makes it possible to accurately simulate PFF processes on intra-urban roads and the output inundation maps (both flood depth and spatial extent) could further be used to identify the road network at risk and to take the appropriate risk mitigation measures (Bates and De Roo 2000; Yu and Lane 2006a, b; Sampson et al. 2012).

Within this study, an integrated methodology is proposed by incorporating flood inundation modelling, transportation disruption (i.e. road closure) detection and risk assessment to measure the impact and risk of PFF on intra-urban road networks. This is the first attempt to apply high resolution 2D hydrodynamic model and flood depth-dependent measure for evaluating the impact of pluvial flooding on road disturbance at the intra-urban level. The city center of Shanghai, China, where roads are in particular prone to pluvial flash flooding, is selected as a case study area. The road inundation risk analysis is focused on transportation disruption rather than on infrastructure damage due to PFFs. The main objectives in this paper are to: (a) develop a step-by-step approach to investigate the transportation impact from temporary pluvial flooding for intra-urban road network; (b) explore the spatio-temporal characteristics of pluvial flash flooding on intra-urban roadways; (c) quantify intra-urban transportation disruption risk under a range of PFF magnitudes. The rest of this paper is organized as follows: Section 2 is devoted to the presentation of the materials and methods, including the introduction of study area, the available data, the description of flood modeling, road impact and risk assessment; Section 3 presents the results and discussions; the conclusions are given in Section 4.

\section{Materials and methods}

\subsection{Study area}


The city center of Shanghai, China has been chosen as study site because it exhibits high risk of pluvial flash flooding and also associated impact of transportation disruption. The study area located at the junction of Huangpu River and Suzhou Creek, bordering with South-North Elevated Highway and Yan'an Elevated Highway (Fig. 1). It covers about $3.25 \mathrm{~km}^{2}$ on the north part of Huangpu District with a mild and low-lying topography (about $3 \mathrm{~m}$ above Wusong Datum). The region belongs to a northern subtropical monsoon climate characterized by four distinctive seasons, receiving an annual average rainfall of 1,122 $\mathrm{mm}$ (Yin et al. 2014). The area is frequently affected by cyclonic storms and intense convectional precipitation occurring especially during the flood season (June to September). According to Quan (2014), pluvial flooding is accounted for more than half of the total flood events from 251 to 2000 in Shanghai, mostly in urban area.

The study site has historically been the city center of Shanghai since its opening to the outside world in the mid nineteenth century. Therefore, it is dominated by various urban landscapes, for instance, crowded buildings, high road intensity and considerable areas of impervious surface except a few green open spaces (e.g. the people's park) in the southwest region. Like most city center, it has a heavy traffic, especially during the morning and evening rush hours. Severe road flooding occurs at least once every few years on average due to flash and heavy rainfalls (Shi et al. 2010; Wu et al. 2012). To protect against intensified pluvial flood hazards, the pumps and sewer systems have been reinforced several times over the past decades. At present, the drainage system in the study area can be divided into two parts: 1) high standard system which is designed to withstand 1 in 3 year rainfall $(49.6 \mathrm{~mm} / \mathrm{h})$ for the central business district, and 2) general system designed to deal with 1 in 1 year rainfall $(36 \mathrm{~mm} / \mathrm{h})$ for the other region.

\subsection{Data availability and processing}

\subsubsection{Rainfall data}


As the external driving force of pluvial flooding, precipitation information should be used as an input to flood hazard analysis. Most of cities in China have their own municipal models of Intensity-Duration-Frequency (IDF) relationships to account for local precipitation characteristics. On the basis of Shanghai rainstorm IDF formula which is developed by Shanghai Municipal Engineering Design Institute and applied for municipal drainage design, the rainfall intensities with the duration of one hour and the return period of 1 in $5,10,20,50$ and 100 years are formulated to cover the probable inundation situations (Yin et al. 2011). The formula can be expressed as follows:

$q=1995.84\left(P^{0.30}-0.42\right) /(t+10+7 \lg P)^{0.82+0.07 \lg P}$

where $q$ is the rainfall intensity, $P$ is the return period of rainfall, and $t$ is the duration of rainfall.

Considering the rainfall temporal variations, Chicago Design Storm, which has been extensively applied in the design storm, is employed to calculate peak intensity and then redistributes the rainfall before and after the peak with the relevant spectrum of durations (Keifer and Chu, 1957). The parameter $r$ (i.e. the ratio of time of the peak to the total), is empirically fixed at 0.4 in Shanghai city. This, in combination with Shanghai IDF analysis, enable the design rainstorms corresponding to the defined return periods. The generated rainfall fields display a spatial uniformity and a 1-minute temporal resolution.

The equations of Chicago method can be written as follows:

$i_{a}=\frac{a \times\left[\frac{(1-c) \times t_{a}}{1-r}+b\right]}{\left(\frac{t_{a}}{1-r}+b\right)^{c+1}}$
$i_{b}=\frac{a \times\left[\frac{(1-c) \times t_{b}}{r}+b\right]}{\left(\frac{t_{b}}{r}+b\right)^{c+1}}$

where $i_{a}$ is the rainfall intensity after the peak $(\mathrm{mm} / \mathrm{min}) ; i_{b}$ is the rainfall intensity before the peak $(\mathrm{mm} / \mathrm{min}) ; t_{a}$ is the time after the peak ( $\min ) ; t_{b}$ is the time before the peak ( $\left.\min \right) ; a, b$ and $c$ are the parameters function of the location and the frequency. 


\subsubsection{Topography data}

In order to represent the topography of urban surface and road network, high resolution airborne LiDAR data of the study site are collected from Shanghai Survey Bureau. The raw LiDAR cloud-points were originally gathered in 2006 using the ALTM3100 system distributed by Optech Incorporated. The data are found to have a root mean square error (RMSE), vertically, of about $0.1 \mathrm{~m}$ and a diameter of about $0.6 \mathrm{~m}$ between each elevation point. A strict quality control procedure and segmentation process are then conducted to remove specific urban surface features, such as trees, from the LiDAR dataset by means of TerraSolid software. Finally, the remaining point cloud is converted to obtain a standard LiDAR Digital Surface Model (DSM) with a gridded resolution of $2 \mathrm{~m}$ (Yin et al. 2016).

\subsubsection{Road data}

An original GIS-based road network dataset used in this study came from the key laboratory of geographic information science, Ministry of Education, East China Normal University. It was further rectified to match well with aforementioned LiDAR-DSM by manual visual interpreting in online maps (e.g. Google and Baidu). The urban roadway were structured according to functions, such as transportation and service. There are three types of road in this area, including the main roads (30 - $40 \mathrm{~m}$ wide), secondary main roads (20 - $24 \mathrm{~m}$ wide) and side roads (14 - $18 \mathrm{~m}$ wide). The road system contains more than 60 roads and over 300 road sections with a total length of $43.2 \mathrm{~km}$ (Fig.1).

\subsection{Flood inundation modeling}

The revised version (FloodMap-HydroInundation2D) of a well-established 2D inundation model (FloodMap), which 
couples hydrological processes (e.g. infiltration, evapotranspiration and drainage) with flood inundation for high-resolution pluvial (surface water) flood modelling in urban environment, was employed to derive pluvial flood risks associated with urban road network. Surface flood routing takes the same structure as the inertial model of Bates et al. (2010), but with a slightly different approach to the calculation of time step. Infiltration over saturation is calculated by the widely used Green-Ampt equation and evapotranspiration is represented using a simple seasonal sine curve for daily potential evapotranspiration (Calder et al. 1983). The amount of runoff loss to the urban storm sewer systems is also considered in the model by scaling the drainage capacity $(\mathrm{mm} /$ hour) for each time step. The details of the model structure have been described in Yu and Coulthard (2015).

The complete pictures of the flood extent, in the form of inundation maps, are not available in Shanghai as there were no remote sensing (i.e. aerial and/or satellite) observations or reliable field surveys for the historical pluvial flood events. Instead, the FloodMap model was calibrated and validated by comparing model prediction of a recent 12 August 2011 pluvial flash flood event, which induced extensive inundation in the study area, particularly for the road network, with its public reported flood incidents ('crowd sourced data'), among which 17 flooded records falls into the study area. Model calibration were undertaken in Yin et al. (2016). A set of optimal parameters (i.e. a hydraulic conductivity value of $0.001 \mathrm{~m} / \mathrm{h}$ and a roughness value of 0.06 ), which generate a good prediction, is used for running with the design flood scenarios. Distributed drainage capacity (i.e. $49.6 \mathrm{~mm} / \mathrm{h}$ in CBD and $36 \mathrm{~mm} / \mathrm{h}$ in the other areas) is incorporated into the model on a cell by cell basis and evapotranspiration is fixed at $3 \mathrm{~mm} /$ day which may be neglected for short-term heavy rainfall in urban environment. Finally, the FloodMap is set up to model 4 hours of simulated time until a steady state water depth has been reached by the end of the simulations.

\subsection{Road impact method}


The transportation impact assessment began with the identification of road network links and the moving vehicles that are exposed to PFF based on the findings from the flood modeling. And then, we used a critical threshold (i.e. $30 \mathrm{~cm}$ ), which referenced the heights (around $25-35 \mathrm{~cm}$ ) of car's air inlets and was adopted for road closures in many cities, to describe the relationship between inundation depth and road disruptions. The flooded road sections are initially identified on a basis of GIS intersection of road network and inundation depths according to the critical threshold. Moreover, an algorithm is developed to extract the start time and total duration for the grids when the water depths rise above $30 \mathrm{~cm}$ throughout the simulations. Meanwhile, a simple rule is used to assist in determining the duration of road closure, with an assumption that traffic conditions for the closed roads update over a regular time interval (e.g. $5 \mathrm{~min}, 15 \mathrm{~min}$ or every half an hour) in urban flood management. In this study, the interval is set at $30 \mathrm{~min}$ to simplify the analysis. This is considered to be adequate as the focus of the study is risk assessment rather than detailed prediction of transportation disruptions. Therefore, the maximum durations can be determined for each identified road section.

In addition to the road failure caused by direct inundation, the potential disruption also depends on the indirect correlation effect (i.e. start time and flood duration) of the linked road sections, which can be measured by GIS network analysis. Even if a road section has not been directly flooded over $30 \mathrm{~cm}$, road closure would still occur during a period when the linked road network failed and it can not find a path or outlet to connect outside the boundaries of the study area. The duration of indirect road disruption was consequently determined by the minimum failure duration of the linked network.

\subsection{Risk assessment model}

Risk can be defined as the possibility of expected damages (or losses) due to hazardous events and vulnerability of 
receptors in a given area during a specific period of time (UNDRO 1991; van Westen 2009). It is often based on economical assessment which is not available for road inundation risk assessment in China' cities due to lack of reliable official or insurance data, but other indicators can also be used (ten Veldhuis and Clemens 2010; Caradot et al. 2011). In our analysis, a new proxy $D_{r}(\mathrm{~km} \bullet \mathrm{h})$ is alternatively created to represent the magnitude of flood-induced road interruptions by combining the submerged road length with its duration. As a consequence, the road risk of each scenario can be calculated by multiplying the $D_{r}$ of a certain flood event by its occurrence probability, with a trend line (risk curve) fitted to each set of scenarios. The consequence $\left(\mathrm{D}_{\mathrm{r}} /\right.$ year) of each scenario is further plotted against the corresponding probability in a graph and an annual risk curve is consequently generated by fitting these points. On this basis, the average annual $D_{r}\left(A_{A D}\right)$ can be found by integration of the road inundation risk over all return periods. It is defined as the area under the risk $\left(D_{r}\right)$ curve and can be calculated as follows:

$A A D_{r}=\int f(x) D(x) d x$

where $f(x)$ is the probability function of a specific pluvial flood event $x$ and $D(x)$ is the road impacts of $x$.

\section{Results and discussion}

\subsection{Road flooding}

The predicted spatial and statistical results of maximum inundations (extent and depth) throughout the simulations for different flood return periods are presented in Fig. 2 and Tab.1 respectively. In general, the derived inundation patterns are characterized by a high degree of consistency among the five scenarios, albeit with various magnitudes corresponding to different return periods. Almost total inundations (above $5 \mathrm{~cm}$ ) are observed in the road networks except scattered ponding in limited open spaces for all the simulations, largely due to the mild relief, flat topography, crowd buildings and in 
particular the low capacity (1 3 year in the study area) of storm sewer drainage network which is usually designed to cope with less than 5 year return period rainfall flooding in China's cities, even for the mega-cities such as Beijing, Shanghai and Guangzhou (Liu 2008). As expected, the maximum inundation extents and depths for road networks gradually increase with increasing recurrence intervals. For the fairly frequent rainfall events (5-year and even 10-year), majority of roads in central business district are associated with shallow water depth and significant inundation $(>20 \mathrm{~cm})$ mainly occurred in some road sections of the western and southern regions because of the relatively low drainage capacity. By contrast, the entire road network in the study region is obviously sensitive to low-frequency flood events as the torrential rainfalls greatly overwhelmed the design capacity of local drainage systems. The total inundation area with water depth higher than $0.3 \mathrm{~m}$ may dramatically increase by approximately 5 times from 5-year to 100-year flood event, indicating that the transportation system and associated moving vehicles in affected roads are very subject to the direct inundation impact from low-frequency floods.

In order to illustrate the road flooding dynamics for each return period, as an example, time evolutions of simulated inundation for the 10-year and 100-year precipitation scenarios are analyzed. Comparison of time series of the road inundation leads to two main findings. Firstly, road flooding is locally originated and synchronized with the timing of rainfall. Road network inundation (i.e. extent and depth) over time increases rapidly during the rainfall and slightly decreases as the flood recedes in each simulation. During the rising stage of rainfall, water flow spreads along the road networks and extensive road flooding can be observed in each scenario. Storm water continues to accumulate in low-lying road sections during the falling limb of rainfall and maximum road inundation is reached after peak rainfall at approximately the 1-1.5 hour of each simulation. And then, flood water gradually recedes through the drainage network, infiltration and evapotranspiration. Secondly, road flooding, in terms of depth and extent, is generally proportionate to the magnitude of precipitation. With the increase in return period, severe road flooding in terms of timing progressively extend 
with slight advance in early stage and significant delay in the receding phase. Water depths in whole road network are shallow $(<20 \mathrm{~cm})$ at 30 -min in the simulation of frequent event, but significant inundations have emerged at the same time in many road sections for low frequency event, suggesting a reduction of traffic emergency response time as increasing rainfall. Furthermore, amount of affected roads rapidly reduce during the receding phase for 10-year flood but the majority of road network is still seriously submerged by 100 -year flood even at the end of the simulation, which means that the recovery time of transportation disruptions will be significantly longer for low frequency flood.

\subsection{Transportation impacts}

Intra-urban road network disruptions for different flood scenarios are identified on the basis of flood modeling (Fig.3). The statistical length (i.e. total and indirect) of road network disruptions for each return period is summarized in Tab.2. The immediate finding is that the municipal road network demonstrates a great impact from increasing short term pluvial flooding which spatiotemporally reduce the connectivity and accessibility. For example, around $37 \%$ of the road network is possibly interrupted by 5 year pluvial flood event, among which more than one third of the affected roads should be totally closed during the simulation. The other roads would be more congested, causing greater travel delays. For 100 year flood, the direct affected road network is predicted to more than double when compared with the 5 year flood, and the closed road length significantly increases to nearly $21 \mathrm{~km}$ accounting for almost half of the total.

Results also show that there is a nonlinear relation between increasing pluvial flooding and indirect responses of road network disruption. Only a few road sections (less than 1 percent) would be indirectly interrupted as a result of the closure of the linked roads and the associated traffic impacts are therefore negligible for fairly frequent events (i.e. 5-year, 10-year and 20-year pluvial flooding). This is largely due to the fact that although many road sections are directly affected in these 
scenarios, there are additional alternative routes available to keep the remaining roadways open. Conversely, a large number of unaffected road network in central business district would be forced to shut down at least 1 to 2 hours in low frequency flood scenarios, indicating an extremely low level of road system connectivity. In addition to some main roads, the majority (around $80 \%$ ) of the municipal transportation system would be paralyzed during the simulations. These results are similar to the studies in other cities (e.g. Portland and Boston) where urban transportation network also demonstrates a greater impact from flooding (Chang et al. 2010; Suarez et al. 2005). Compared with flood impact on regional road system, urban transportation have less capacity to reorganize itself (Freiria et al. 2014).

\subsection{Risk analysis}

The flood impact function and annual risk density curve for intra-urban road network are shown in Fig.4. $\mathrm{D}_{\mathrm{r}}$ demonstrates a significant logarithmic trend with the increasing return periods. It rapidly increased from $47 \mathrm{~km} \bullet \mathrm{h}$ for 5 -year flood to 125 $\mathrm{km} \bullet \mathrm{h}$ in 100-year event, suggesting that the entire road network would be disrupted on average about 1 to 3 hours. Furthermore, the risk curves are best described with a power function with an $R^{2}$ of 0.99 or greater. The specific annual risk increases from low frequency flood to frequent event and the total $\mathrm{AAD}_{\mathrm{r}}$ is finally calculated to be $13.2 \mathrm{~km} \bullet \mathrm{h}$ disruption for the road network. A thorough analysis of the risk curves combined with the findings in section 3.1 and 3.2 also reveal that given the relative low risks, flood events with occurrence probability less than 0.02 are also considered to be unacceptable for the municipal road network because of the potential catastrophic impacts on urban transportation function. The findings therefore resemble the assessment of pluvial flood risk made by Yin et al. (2011) in another community-Jing'an of Shanghai and Zhou et al. (2012) in Skibhus, Denmark, showing that road inundation risk would be relatively significant in the urbanized areas. 


\subsection{Risk mitigation}

Risk analysis of pluvial flood-induced road disruption demonstrates that intra-urban road network is particularly susceptible to fairly frequent pluvial flooding. Appropriate adaptation should be implemented to mitigate the expected annual risk. This can be addressed from two perspectives, one relevant to structural measures, and the other related to non-structural options. From the engineering perspective, the drainage capacity may be increased to deal with at least 5 year rainfall for highly affected roads through pipe enlargement and/or construction of underground reservoirs. Moreover, low impact measures (such as depressed green, green roofs and permeable paving) can provide not only a blue/green environment but also an efficient way of reducing and storing runoff volume. For example, the large open green spaces (e.g. the people's park in this case) is not physically and socio-economically vulnerable to pluvial flooding. If the ground elevation could be lowered, water will accumulate to this area, thus lessen the risk of nearby roads. More recently, non-structural approaches, which are not involving physical construction, have proved to be robust in some situations through a road inundation forecasting and warning, emergency transportation management, and risk spreading (e.g. insurance). Finally, as an important supplement, prepositioning of temporary drainage facilities at the critical intersections could significantly reduce or even avoid potential indirect disruption risk of road network.

4 Conclusions

This paper presents a novel approach to identify the impact and risk of pluvial flash flooding on intra-urban road networks through an integration of pluvial flood numerical modelling, GIS-based road failure analysis and risk assessment model. The methodology proposed here could be adopted for applications in other PFF-prone urban areas facing similar road problem. The results obtained are promising and indicate that given the flash nature of rainfall, extensive pluvial flood 
mainly occurred in municipal roadways within a relatively long duration. The road flooding depends not only on precipitation timing and intensity, but also relies on local drainage capacity and topographic characteristics. Although increasing pluvial flood may lead to a proportionate but non-linear impact on the functions (e.g. connectivity and accessibility) of urban road system, we should give priority to common and fairly frequent events as there is a high degree of positive correlation between risk and probability.

Such detailed road risk assessment may contribute to better understand the potential impacts of pluvial flash flooding on intra-urban transportation sector, and to help policy makers and other concerned stakeholders develop proper measures for urban flood risk management. However, in order to arrive at more robust conclusions, this study could be improved in the following aspects: 1) future trends such as climate change and urban development should be incorporated because they will evolve over time and further change the pluvial flood risk associated with road network; 2) apart from considering the road disruption, traffic delay due to pluvial flash flood could be assessed to provide a more complete picture of road impacts and risk; 3) including economic estimation of road inundation risk would be a significant progress in the future work, particularly for urban areas in developing countries.

Acknowledgments This work was supported by the Open Research Fund of State Key Laboratory of Estuarine and Coastal Research (Grant No: SKLEC-KF201407), the National Natural Science Foundation in China (Grant No: 41201550, 41371493, 71373084), Project of Joint Center for Shanghai Meteorological Science and Technology (Grant No: 2015-03), Innovation Program of Shanghai Municipal Education Commission (Grant No: 13YZ061, 13ZZ035). 


\section{References}

Bates, P. D., De Roo, A. P. J., 2000. A simple raster-based model for flood inundation simulation. J. Hydrol. 236, 54-77.

Bates, P. D., Horritt, M., Fewtrell, T., 2010. A simple inertial formulation of the shallow water equations for efficient two-dimensional flood inundation modelling. J. Hydrol. 387, 33-45.

Calder, I. R., Harding, R. J., Rosier, P. T. W., 1983. An objective assessment of soil moisture deficit models. J. Hydrol. 60, 329-355.

Caradot, N., Granger, D., Chapgier, J., Cherqui, F., Chocat, B., 2011. Urban flood risk assessment using sewer flooding databases. Water Sci. Technol. 64, 832-840.

Chang, H., Lafrenz, M., Jung, I., Figliozzi, M., Platman, D., Pederson, C., 2010. Potential Impacts of Climate Change on Flood-Induced Travel Disruptions: A Case Study of Portland, Oregon, USA. Ann. Assoc. Am. Geogr. 100, 1-14.

Chang, M., Tseng, Y., Chen, J., 2007. A scenario planning approach for the flood emergency logistics preparation problem under uncertainty. Transport. Res. E 43, 737-754.

Du, J. K., Qian, L., Rui, H. Y., Zuo, T. H., Zheng, D. P., Xu, Y. P., Xu, C. Y., 2012. Assessing the effects of urbanization on annual runoff and flood events using an integrated hydrological modeling system for Qinhuai River basin, China. J. Hydrol. 464-465, 127-139.

Drobot, S. D., Benight, C., Gruntfest, E. C., 2007. Risk factors for driving into flooded roads. Environ. Hazards 7, $227-234$.

Freiria, S., Tavares, A. O., Julião, R. P., 2014. The Multiscale Importance of Road Segments in a Network Disruption Scenario: A Risk-Based Approach. Risk Anal. 35, 484-500

Hung, N. Q., Babel, M. S., Weesakul, S., Tripathi, N. K., 2009. An artificial neural network model for rainfall forecasting in Bangkok, Thailand. Hydrol. Earth Syst. Sci. 13, 1413-1425.

IPCC, 2013. Climate change 2013: The physical science basis. Cambridge: Cambridge University Press.

Keifer, C. J., Chu, H. H., 1957. Synthetic storm patterns for drainage design. ASCE J. Hydraul. Div. 83, 1332.1-1332.25. 
Liu, X. T., 2008. Shanghai flood prevention handbook. Shanghai: Shanghai Popular Science Press (in Chinese).

Mejia, J. M., Moglen, G. E., 2010. Impact of the spatial distribution of imperviousness on the hydrologic response of an urbanizing basin. Hydrol. Process. 24, 3359-3373.

Naulin, J. P., Payrastre, O., Gaume, E., 2013. Spatially distributed flood forecasting in flash flood prone areas: Application to road network supervision in Southern France. J. Hydrol. 486, 88-99.

NYC Emergency Management, 2014. 2014 New York City hazard mitigation plan. Final report, April 2014. http://www1.nyc.gov/assets/em/downloads/pdf/hazard_mitigation/plan_update_2014/final_nyc_hmp.pdf.

Pitt, M, 2008. Learning lessons from the 2007 floods (The Pitt Review). London: Cabinet Office. http://archive.cabinetoffice.gov.uk/pittreview/thepittreview/final_report.html.

Quan, R. S., 2014. Risk assessment of flood disaster in Shanghai based on spatial-temporal characteristics analysis from 251 to 2000. Environ. Earth Sci. 72, 4627-4638.

Ramos, M. H., Creutin, J. D., Leblois, E., 2005. Visualization of storm severity. J. Hydrol. 315, 295-307.

Sampson, C., Fewtrell, T., Duncan, A., Shaad, K., Horritt, M., Bates, P., 2012. Use of terrestrial laser scanning data to drive decimetric resolution urban inundation models. Adv. Water Resour. 41, 1-17.

Shi, Y., Shi, C., Xu, S. Y., Sun, A. L., Wang, J., 2010. Exposure assessment of rainstorm waterlogging on old-style residences in Shanghai based on scenario simulation. Nat. Hazards, 53: 259-272.

Smith, J. A., Baeck, M. L., Villarini, G., Welty, C., Miller, A. J., Krajewski, W. F., 2012. Analyses of a long-term high-resolution radar rainfall data set for the Baltimore metropolitan region. Water Resour Res. 48, W04504.

Sohn, J., 2006. Evaluating the significance of highway network links under the flood damage: An accessibility approach. Transport. Res. A 40, 491-506.

Suarez, P., Anderson, W., Mahal, V., Lakshmanan, T., 2005. Impacts of flooding and climate change on urban transportation: A systemwide performance assessment of the Boston Metro Area. Transport. Res. D 10, 231-244. 
Suriya, S., Mudgal, B. V., 2012. Impact of urbanization on flooding: The Thirusoolam sub watershed-A case study. J.

Hydrol. 412-413, 210-219.

ten Veldhuis, J. A. E., Clemens, F. H. L. R., 2010. Flood risk modelling based on tangible and intangible urban flood damage quantification. Water Sci. Technol. 62, 189-195.

UNDRO, 1991. Mitigating natural disasters: phenomena, effects and options. United Nations Disaster Relief Coordinator, United Nations: New York.

van Westen, C. (ed), 2009. Multi-hazard risk assessment, Distance education course Guide book. Bangkok, United Nations University-ITC.

Versini, P. A., Gaume, E., Andrieu, H., 2010a. Assessment of the susceptibility of roads to flooding based on geographical information-test in a flash flood prone area (the Gard region, France). Nat. Hazards Earth Syst. Sci. 10, $793-803$.

Versini, P. A., Gaume, E., Andrieu, H., 2010b. Application of a distributed hydrological model to the design of a road inundation warning system for flash flood prone areas. Nat. Hazards Earth Syst. Sci. 10, 805-817.

Wright, D. B., Smith, J. A., Villarini, G., Baeck, M. L., 2012. The hydroclimatology of flash flooding in Atlanta. Water Resour Res. 48, W04524.

Wu, X. D., Yu, D. P., Chen Z, Wilby, R., 2012. An evaluation of the impacts of land surface modification, storm sewer development, and rainfall variation on waterlogging risk in Shanghai. Nat. Hazards 63, 305-323.

Yin, J., Ye, M. W., Yin, Z. E., Xu, S. Y., 2015. A review of advances in urban flood risk analysis over China. Stoch. Environ. Res. Risk Assess. 29, 1063-1070.

Yin, J., Zhang, Q., 2014. A comparison of statistical methods for benchmarking the threshold of daily precipitation extremes in the Shanghai metropolitan area during 1981-2010. Theor. Appl. Climatol. 120, 601-607.

Yin, J., Yu, D. P., Wilby, R., 2016. Modelling the impact of land subsidence on urban pluvial flooding: A case study of downtown Shanghai, China. Sci. Total Environ. 544, 744-753. 
Yin, Z. E., Yin, J., Xu, S. Y., Wen, J., 2011. Community-based scenario modelling and disaster risk assessment of urban rainstorm waterlogging. J. Geogr. Sci. 21, 274-284.

Yu, D. P., Lane, S. N., 2006a. Urban fluvial flood modelling using a two-dimensional diffusion wave treatment, part 1: mesh resolution effects. Hydrol. Process. 20, 1541-1565.

Yu, D. P., Lane, S. N., 2006b. Urban fluvial flood modelling using a two-dimensional diffusion wave treatment, part 2: development of a sub grid-scale treatment. Hydrol. Process. 20, 1567-1583.

Yu, D. P., Coulthard, T. J., 2015. Evaluating the importance of catchment hydrological parameters for urban surface water flood modelling using a simple hydro-inundation model. J. Hydrol. 524, 385-400.

Zhang, W., Li, S. M., Shi, Z. N., 2012. Formation causes and coping strategies of urban rainstorm waterlogging in China. J. Nat. Disasters 21, 180-184 (in Chinese).

Zhou, Q., Mikkelsen, P. S., Halsnæs, K., Arnbjerg-Nielsen, K., 2012. Framework for economic pluvial flood risk assessment considering climate change effects and adaptation benefits. J. Hydrol. 414-415, 539-549.

Tab. 1 The statistical inundation area and percentage of different water depths for each flood scenario, and inundation area listed in this table is not limited to road network. 


\begin{tabular}{cccccc}
\hline \multirow{2}{*}{ Water depth $(\mathrm{m})$} & \multicolumn{5}{c}{ Inundation area $\left(\mathrm{km}^{2}\right)$ and percentage $(\%)$ of the total area } \\
\cline { 2 - 6 } & 5-year & 10-year & 20-year & 50-year & 100 -year \\
\hline $0-0.05$ & $2.81(86.31 \%)$ & $2.75(84.37 \%)$ & $2.69(82.6 \%)$ & $2.63(80.83 \%)$ & $2.59(79.72 \%)$ \\
$0.05-0.1$ & $0.17(5.13 \%)$ & $0.16(4.85 \%)$ & $0.14(4.42 \%)$ & $0.13(3.92 \%)$ & $0.12(3.67 \%)$ \\
$0.1-0.2$ & $0.17(5.12 \%)$ & $0.19(5.76 \%)$ & $0.18(5.67 \%)$ & $0.18(5.52 \%)$ & $0.17(5.28 \%)$ \\
$0.2-0.3$ & $0.07(2.07 \%)$ & $0.09(2.89 \%)$ & $0.12(3.79 \%)$ & $0.14(4.25 \%)$ & $0.14(4.22 \%)$ \\
$0.3-0.5$ & $0.03(1.01 \%)$ & $0.06(1.70 \%)$ & $0.09(2.83 \%)$ & $0.14(4.23 \%)$ & $0.17(5.12 \%)$ \\
$>0.5$ & $0.01(0.36 \%)$ & $0.01(0.44 \%)$ & $0.02(0.69 \%)$ & $0.04(1.26 \%)$ & $0.06(1.99 \%)$ \\
\hline
\end{tabular}

Tab. 2 The statistical length of road network disruption for different duration in each flood scenario, and the total length of the road network is $43.2 \mathrm{~km}$. 


\begin{tabular}{cccccc}
\hline \multirow{2}{*}{ Duration (hour) } & \multicolumn{5}{c}{ Total (indirect disruption) length $(\mathrm{km})$} \\
\cline { 2 - 5 } & 5 -year & 10 -year & 20 -year & 50 -year & 100 -year \\
\hline $0-0.5$ & $0.65(/)$ & $0.83(/)$ & $0.39(0.14)$ & $0.43(0.14)$ & $0.18(/)$ \\
$0.5-1$ & $1.60(/)$ & $0.95(/)$ & $1.09(/)$ & $5.11(3.94)$ & $1.17(0.31)$ \\
$1-1.5$ & $0.24(/)$ & $1.48(/)$ & $1.52(/)$ & $0.87(/)$ & $0.94(0.05)$ \\
$1.5-2$ & $2.22(0.14)$ & $0.71(/)$ & $1.66(0.16)$ & $0.71(/)$ & $4.34(2.70)$ \\
$2-2.5$ & $0.91(/)$ & $0.67(/)$ & $1.11(/)$ & $1.30(0.19)$ & $0.69(/)$ \\
$2.5-3$ & $1.54(/)$ & $1.87(/)$ & $1.96(0.10)$ & $2.08(/)$ & $1.20(0.12)$ \\
$3-3.5$ & $2.84(/)$ & $5.24(/)$ & $5.82(0.11)$ & $7.58(0.17)$ & $7.37(0.11)$ \\
$3.5-4$ & $5.96(/)$ & $7.78(0.08)$ & $12.31(/)$ & $16.44(/)$ & $20.81(/)$ \\
Total & $15.95(0.14)$ & $19.52(0.08)$ & $25.85(0.51)$ & $34.52(4.44)$ & $36.68(3.29)$ \\
\hline
\end{tabular}




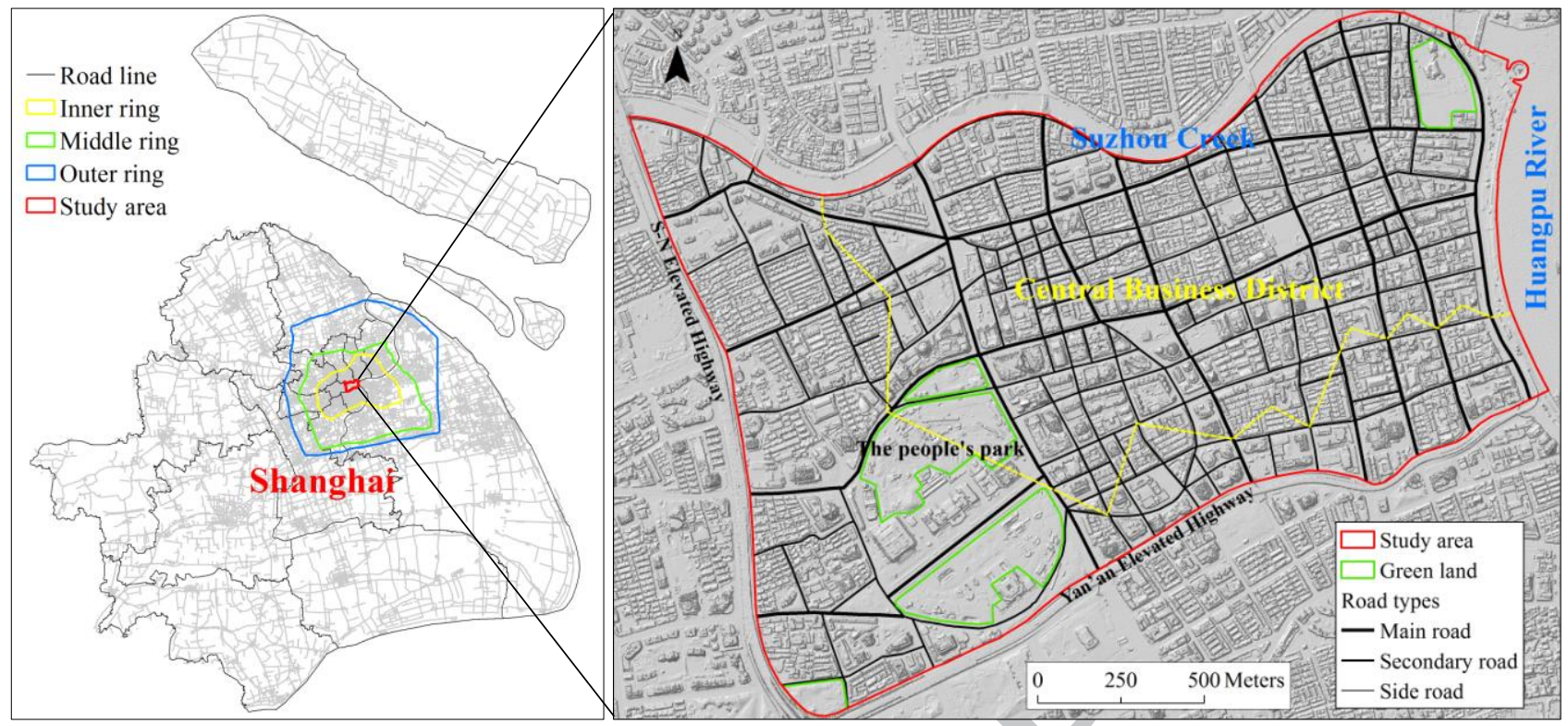

Fig. 1 Location of the study area (right) in Shanghai (left). 

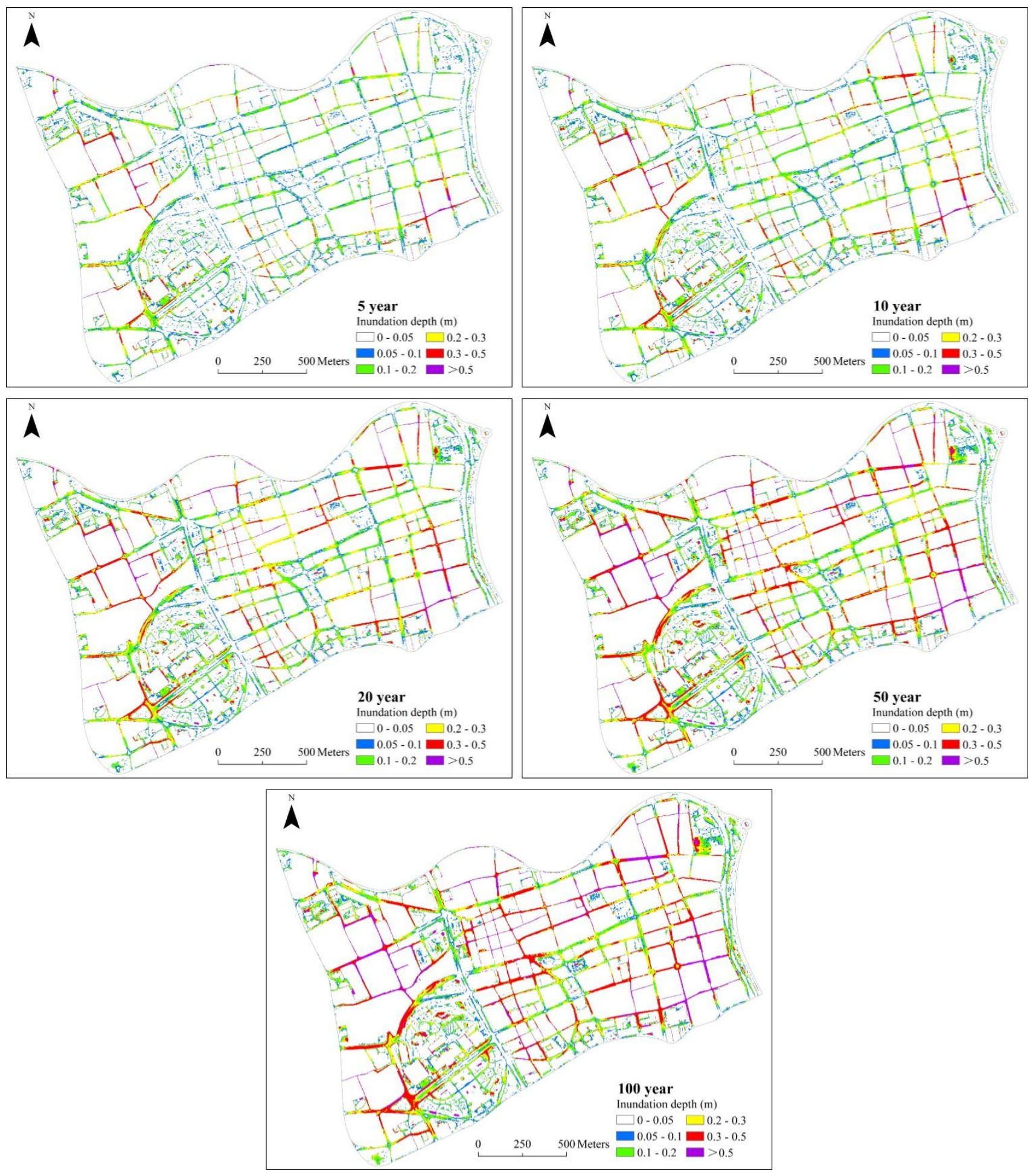

Fig.2 The simulated maximum inundation maps for different flood return periods 

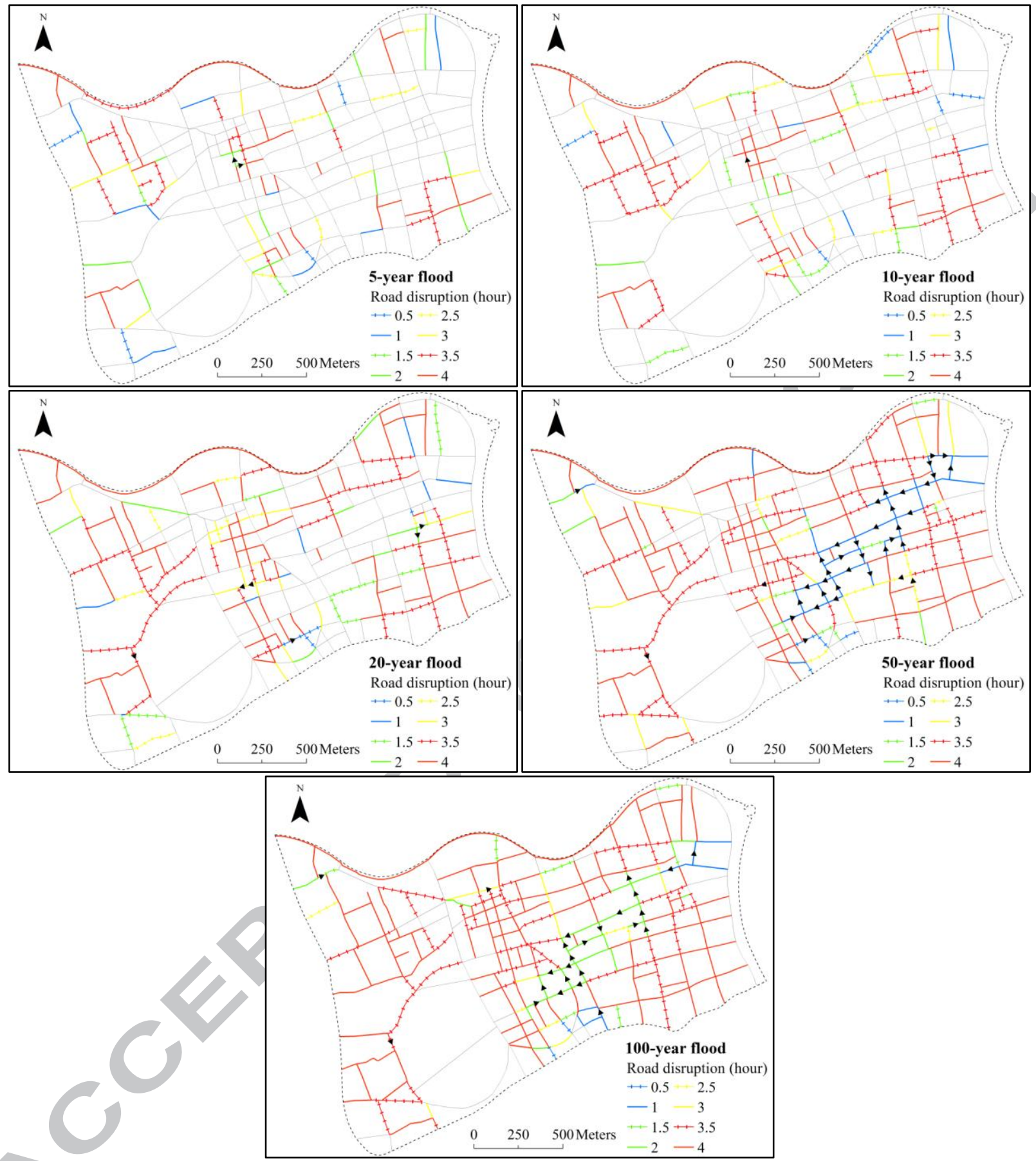

Fig.3 Road network disruptions in each flood scenario, the black arrow represents indirect road disruption as a result of the closure of the linked roadways. 


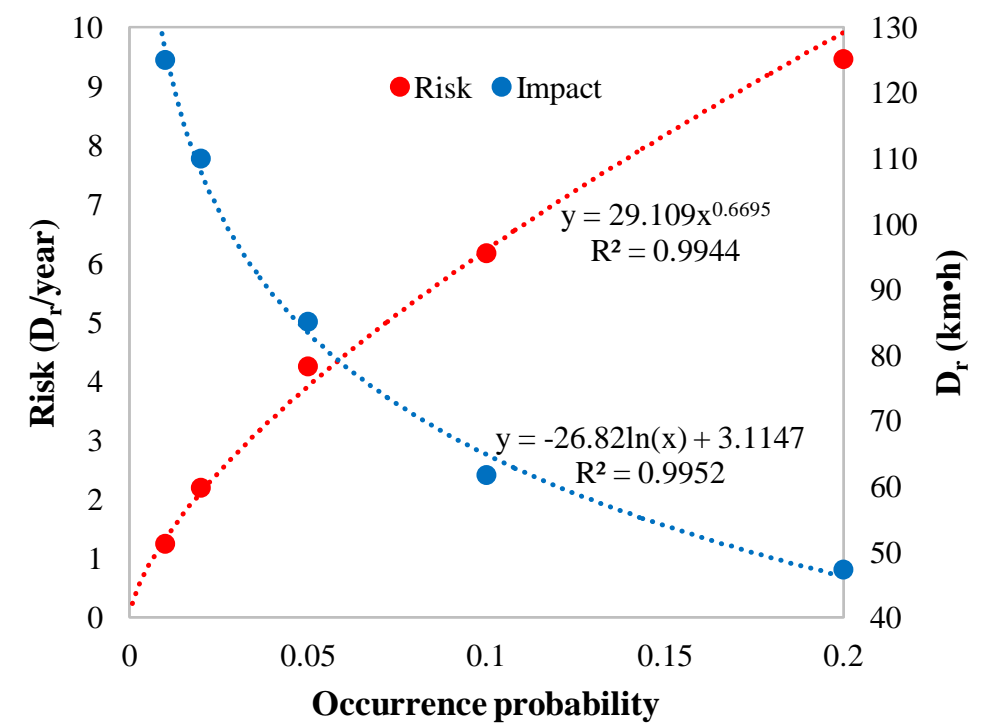

Fig.4 Flood impact function (blue dot line) and annual risk curve (red dot line) for intra-urban road network. 
Highlights:

1. A novel methodology is presented to evaluate the impact and risk of pluvial flash flood on intra-urban road network.

2. An inundation model coupled with GIS-based road network is used to assess the impact of flooding on road disturbance at the intra-urban level.

3. Pluvial flash flood is found to lead to proportionate but nonlinear impact on intra-urban road inundation risk.

4. Current level of protection needs to be improved in order to avoid catastrophic impacts on urban transportation function of the city. 